\title{
Alterations in Smell or Taste
}

National Cancer Institute

\section{Source}

National Cancer Institute. Alterations in Smell or Taste. NCI Thesaurus. Code C5038.

A change to taste and/or olfactory perception resulting from disease processes or treatment. 